\title{
TOMATO MATURITY CLASSIFICATION VIA IMAGE ANALYSIS
}

\author{
Yamani, M. A. ${ }^{1}$, Kabany, A. G. ${ }^{2}$, and Attar, M. Z. ${ }^{3}$
}

\begin{abstract}
This study aims to investigate the possibilities of using a simple image processing technique to evaluate tomato fruit quality. According to the USDA standard, green, pink and red tomatoes maturity coloring index is used to evaluate fruit quality. Maturity stage of fresh tomato fruit is an important factor that affects the fruit quality during ripening and marketability after ripening. Images obtained at top, bottom, side, and fruit opposite side, analyzed through algorithm were created in MATLAB computer software. Results of the image analysis are compared to the measured and calculated values of fruit physical properties and mechanical characteristics (dimensions, sphericity, rupture force and firmness) changes due to changes of maturity stages. Results at different ripening stages indicated that the captured image data at the bottom of tomato fruit were the most accurate to assist the fruit maturity. Results indicated that the proposed image processing technique for assessment of tomato fruit was accurate by $98 \%$.
\end{abstract}

Keywords: Classification, Image Processing, Tomato maturity, Firmness, Rupture, Color index.

\section{INTRODUCTION}

7 omato (lycopersicon esculentum), is a major vegetable crop in Egypt which is cultivated in 550 to 600 thousands faddans,

producing 10 million tons yearly. Egypt ranked fifth in the world in the production of tomato (FAO statistics, 2012). In general, sorting of agricultural products manually according to fruit color, texture, shape, size, and common defects is tedious, time-consuming, and non-consistent due to human subjectivity, visual stress and fatigue. With absent trained and qualified worker to apply the international standards, image processing is promising as a non-destructive sorting technique. Atherton and Rudich (1986) showed that fruit quality factors such as size, color, firmness and nutritive value are the most important factors that influence consumers' purchase and consumption.

\footnotetext{
${ }^{1}$ Demonstrator, and ${ }^{2,3}$ Associate Prof.; Dept. Ag. Eng. Ain-Shams Uni., Egypt.
} 
Mohsenin (1986) reported that the physical characteristics of any material such as shape, size, volume, and surface area are important in solving many problems associated with design or development of specific machines in addition behavior analysis of material handling. Kabas et al. (2006); Kilickan and Guner (2008) described tomato's mechanical properties that mainly include rupture and penetration force, deformation at rupture and firmness of whole tomato fruit and its components of different varieties at various stages of ripening. He described tomato's physical properties (size, density, color, shape, volume, mass and porosity) as necessary parameters for the design of harvesting, transporting, cleaning, packing, storing, and processing equipment.

De Grano and Pabico (2007) reported that tomato color is the most important visible characteristic used to assess ripeness and shelf life, and is a major factor in the consumer's purchase decision. The degree of ripeness is usually estimated visually by human graders who compare the tomato color to a classification chart. This manual practice of tomato maturity classification often results in errors due to human subjectivity, visual stress and fatigue. Shewfelt et al. (1987) mentioned that tomato color alone was not accurate enough to establish relationship between firmness and estimated shelf life. Edan et al. (1997) developed an automatic sorting machine for sorting fresh market tomatoes using fruit color and firmness measurements. Sirisomboon et al. (2012) evaluated textural mechanical properties of tomato at three different stages of maturity (mature green, pink, and red) by the puncture test. And the results showed that initial firmness, average firmness, rupture force, toughness, and deformation at the rupture point were sensitive to the maturity stages. Ghazavi et al. (2013) determined the dimensions of tomato by image processing technique including filtering, conversion to gray scale image and conversion to binary image. The images were labeled and the main thresholds were calculated according to maximum object area, then the dimensions were determined. The results showed that image processing provides an accurate, simple, rapid and non-invasive method to determine tomato size. A digital image analysis and pattern recognition techniques developed by Sarkar and Wolfe (1985) evaluated the quality of fresh market tomato based on size, shape, and surface 
defects. kabany (2002) investigated tomatoes maturity via color image analysis proving the feasibility of using image processing in determining quality of tomato fruits. Zhang et al. (2009) developed a machine vision system to automatically sort cherry tomato according to maturity. Tomatoes were classified into three categories (unripe, half-ripe, and ripe). Images were captured in the RGB color space. The principle component analysis results showed that ripe tomatoes were distinguished from immature and half ripe tomatoes. The machine was able to correctly classify $93.2 \%$ of tomato samples. Ewida et al. (2014) used a computer vision technique to sort the palm-date fruit according to color, size and texture. Mohammadia et al. (2015) developed an automatic algorithm to classify tomato based on color. Physical, mechanical and nutritional properties of fruits were determined to compare the results of image analysis and visual classification. Hassan et al. (2015) evaluated quality parameters of lemon fruits at different maturity stages using color analysis. This study aims to investigate a simple image processing technique to evaluate quality of the tomato fruit.

\section{MATERIALS AND METHODS}

The tomato samples of El-Basha1077 variety were obtained from the field of the Faculty of Agriculture, Ain-Shams University located at Shubra Qaliubiya Governorate - winter season. Samples were collected at three maturity stages (green, pink, and red) based on USDA standard classification of tomato maturity USDA. (1976)as shown in figure 1.

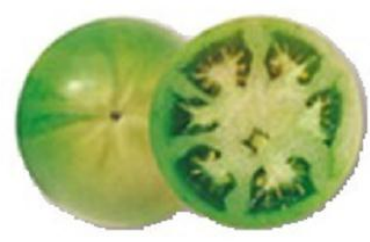

(a)

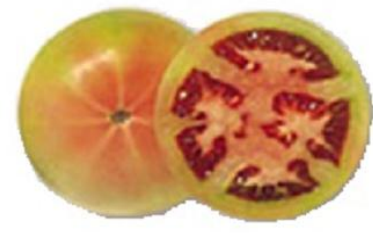

(b)

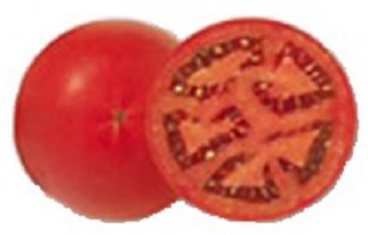

(c)

Figure 1: Tomato samples; green (a); pink (b); and red (c).

The tomato image acquisition set was constructed at the Bio-system Engineering Laboratory, Agricultural Engineering Department, Faculty of Agriculture, Ain-Shams University. A controlled light chamber was constructed to capture extract tomato feature for image analysis. The internal size of the light box is $70 \mathrm{~cm}$ (width) $\times 70 \mathrm{~cm}$ (length) $\times 50 \mathrm{~cm}$ 
(height).Two fluorescence lamps (TL-D Delux, 18W/965, Philips) were attached as illustrated in figure 2. These lamps were chosen to set the color temperature to D65 $(6500 \mathrm{~K})$, a common light source used in fruit color measurement. Both lamps were covered with diffuse battens Kang et al. (2008). Tomato samples were set at $50 \mathrm{~cm}$ under the Samsung ST65 digital camera (14 Mega Pixel resolution, made in Japan). Image digital JPEG data format were saved on PC (Intel Processor, i3, $2.4 \mathrm{GHz}$, and 3 GB of RAM) for further analysis and evaluations.

Dimensions: The three linear dimensions namely as major diameter (D1), intermediate diameter (D2) and height $(\mathrm{H})$, shown in figure 3, were measured by using a digital vernier caliper with measuring range $0-150$ $\mathrm{mm}$ and $.03 \mathrm{~mm}$ accuracy.
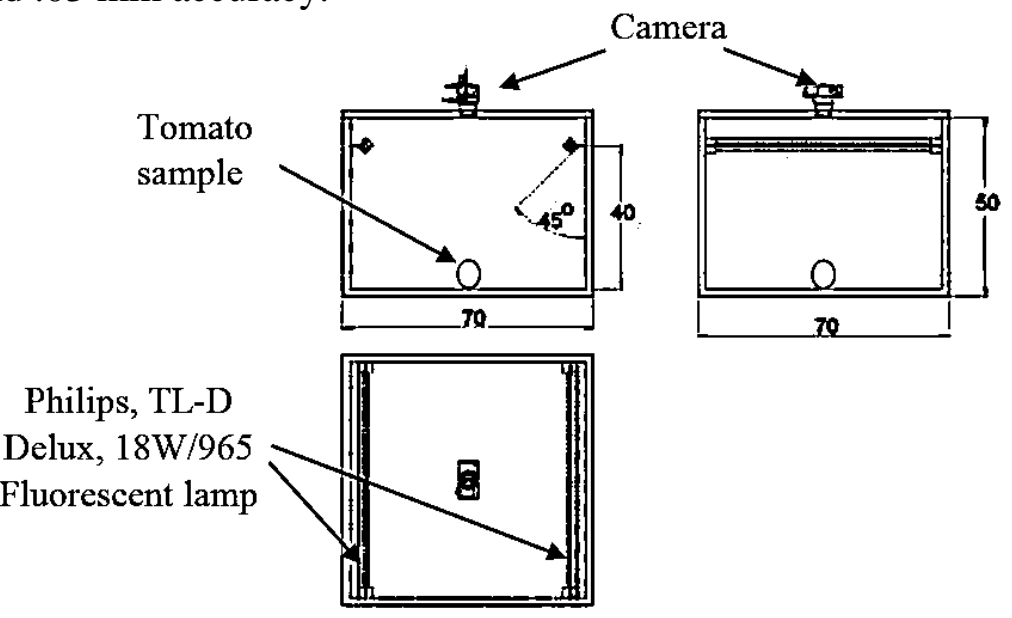

Figure 2: Image capturing chamber (dimensions in centimeter).
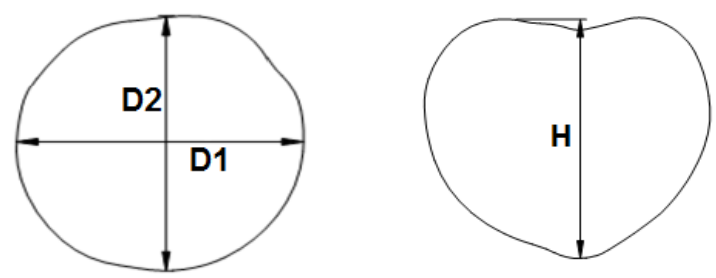

Figure 3: Tomato fruit major diameter (D1), intermediate diameter (D2), and height $(\mathrm{H})$.

Geometric diameter $(\mathbf{D g})$ of the tomatoes was calculated according to Mohsenin (1986).

$$
D_{g}=(D 1 * D 2 * H)^{\frac{1}{3}}
$$


Sphericity (Sph):According to Stroshine \& Hamann (1994), the tomato sample shape was considered as an ellipsoid. And Sph. was calculated from equ.2

$$
S p h=\frac{D_{g}}{D 1}
$$

Where Dg is the geometrical diameter, and D1 is the major diameter.

Firmness test was conducted according to Batu (1998 \& 2004) by Tinius Olsen bench top materials testing machine model H5ks, USA as shown in figure 4. Tomato fruits were tested with a flat-ended $(6 \mathrm{~mm}$ in diameter) stainless steel probe penetrating samples at four positions with Speed of $50 \mathrm{~mm} / \mathrm{min}$ as shown in figure 5 .

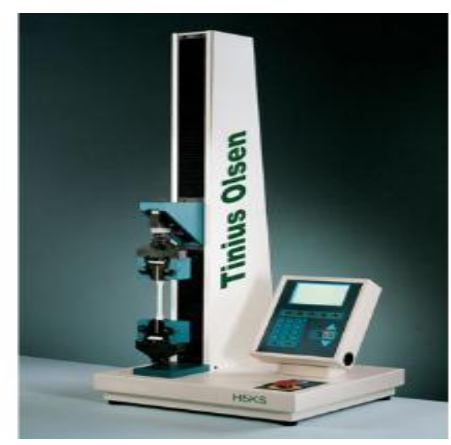

Figure 4: Tinius Olsen bench top materials testing machine model H5ks, USA.
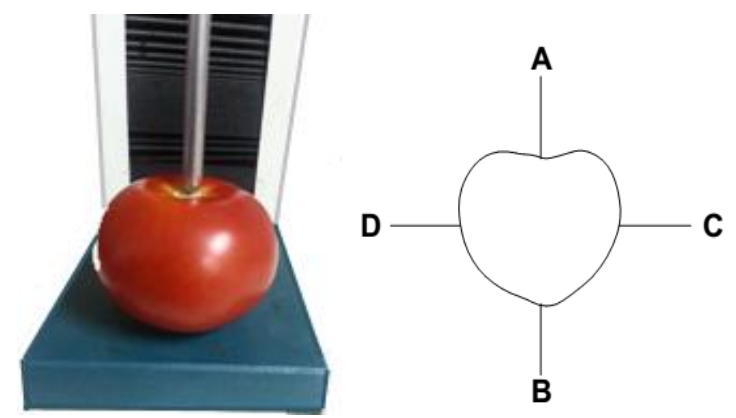

Figure 5: Rupturing test on tomato sample, showing penetration at four locations (on the fruit top (A), bottom (B), and two symmetric points of each sample $(\mathrm{C}, \mathrm{D})$.

According to Sirisomboon et al. (2012), the parameters from the puncture test are the rupture force (peak force, which is traditionally used 
for indicating the firmness), deformation at the rupture point and average firmness as shown in figure $\mathbf{6}$ which were determined.

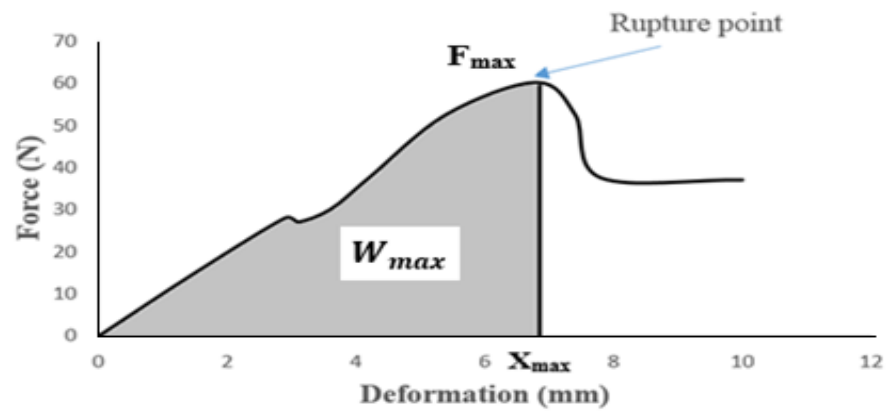

Figure 6: Force - deformation test obtained by puncture test Sirisomboon et al. (2012).

Where $\mathbf{X}_{\max }$ is the maximum penetration distance $(\mathrm{mm}), \mathbf{F}_{\max }$ is the maximum penetration force $(\mathrm{N})$ and Average firmness $(\mathrm{N} / \mathrm{mm})=\mathbf{F}_{\max }$ $/ \mathbf{X}_{\max }$.

Tomato maturity classification by IP method includes image acquisition and image processing. These steps are further elaborated in the following sub-sections. Figure 7 summarizes the procedures involved.

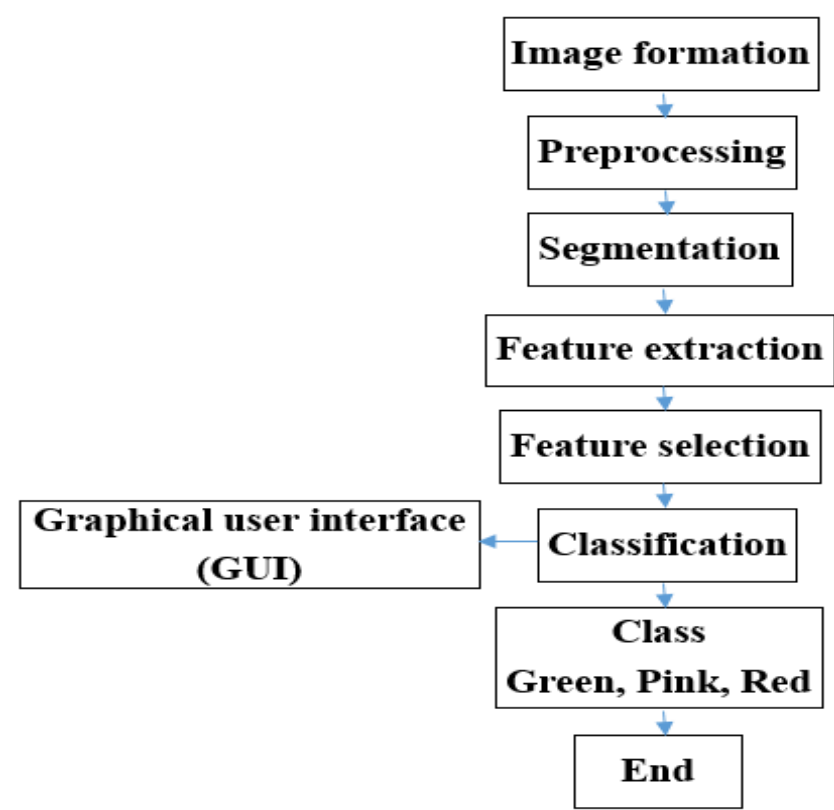

Figure 7: Procedure used to generate the pattern classification algorithm to determine tomato color. 
Image formation and pre-processing: After taking the digital images from image capturing chamber they must be preprocessed to improve their quality before they are analyzed. In addition, in this step the image color is converted to a grayscale image, called the intensity image.

Segmentation: The object of interest is separated from the background and other secondary entities Da Fontoura and Marcondes (2001). The segmentation process involved the following steps: (1) conversion of color image to grey-scale values; (2) application of a threshold and background subtraction to obtain the binary image; (3) closing the small noisy holes within the object of interest; (4) overlapping the contour of the binary image to the original color image.

Feature extraction and selection: The color parameters $\left(L^{*}, a^{*}, b^{*}\right)$ were measured in each sample of tomato. the images were evaluated $\left(818^{*} 527\right.$ pixels) in rectangular coordinates $\left(\mathrm{L}^{*}, \mathrm{a}^{*}, \mathrm{~b}^{*}\right)$. The $\mathrm{L}^{*}$ parameter (luminosity) is an attribute by which a surface emits more or less light and can take values between 0 (absolute black) to 100 (absolute white). The parameters $a^{*}$ and $b^{*}$ represent the chromaticity, where $a^{*}$ defines the red-green component (red for positive values and green for negative values) and the $b^{*}$ parameter defines the yellow-blue component (yellow for positive values and blue for negative values) Leon et al. (2006).

Classification: After processing tomato image as shown in figure 8 maturity stages of tomato are gauged according to the extent of coverage (as a percentage) of red coloring on the fruit surface. Although working with the red plane of the RGB (red, green, blue) color system, on which digital images are based, seems to be a direct option, the $a^{*}$ plane of the CIE L*a*b* color model provides a systematic and more consistent level of color because of decoupling of the luminance information from the hue values. This is especially useful when small changes in lighting intensity are expected. 
Original image, RGB image file format with resolution $1024 \times 768$ pixels.

Gray image converted to gray intensities using the function 'rgb2gray'.

Segmented binary image Partition of the filtered image using a threshold $\mathbf{T}=\mathbf{. 5 6 5}$, converted to gray binary image using the function 'im $2 \mathrm{bw}$ '.

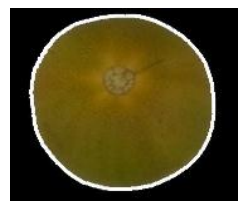

Edge detection Using the Laplacian of Gaussian method using the function 'edge'.

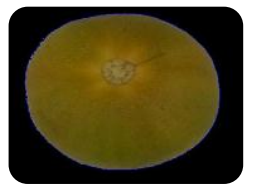

Maturity checking by color.

-The area of surface with red pixel is estimated.

-The ratio of red pixel area to the total area is obtained.

Figure 8:- Scheme for maturity checking using MATLAB.

Pavithra et al. (2015) stated that tomato maturity stage can be determined by a set of summarized routines as:

1. Separating tomato image (foreground) from the background,

2. Determining tomato projection area,

3. Finding number of red pixel (represent cell red pigments) in the tomato projection area,

4. Calculating ratio of red pixels number to the tomato's total area according to equation 3.

$$
\mathbf{R}_{\mathbf{i}}=\frac{\mathbf{D}_{\mathbf{r}}}{\mathbf{D}_{\mathbf{a}}} * 100
$$

Where $\mathbf{R}_{\mathbf{i}}$ is the percentage ratio as measurement at specific maturity stage of the tomato sample $\mathbf{i}, \mathbf{D}_{\mathbf{r}}$ is the number of red pixels (threshold in the $\mathrm{a}^{*}$ plane), and $\mathbf{D}_{\mathbf{a}}$ is the total number of pixels (threshold on the $\mathrm{L}^{*}$ plane), and the maturity stages are as follows:

1- Green maturity stage at $\quad \mathbf{R}_{\mathbf{i}}=\mathbf{0}$, 
2- Pink maturity stage at $\mathbf{0 . 3}<\mathbf{R}_{\mathbf{i}}<\mathbf{0 . 6}$,

3- Red maturity stage at $\quad \mathbf{R}_{\mathbf{i}}>\mathbf{0 . 9}$

The extraction of image color characteristics was performed on a graphical user interface (GUI) created in MATLAB described below.

Figure 9 represents the image of tomato stage (Pink) after clicking the maturity button. From the observation based on figure below, the surface of captured image is Pink color, tomato shelf life: 7 to 14 days.

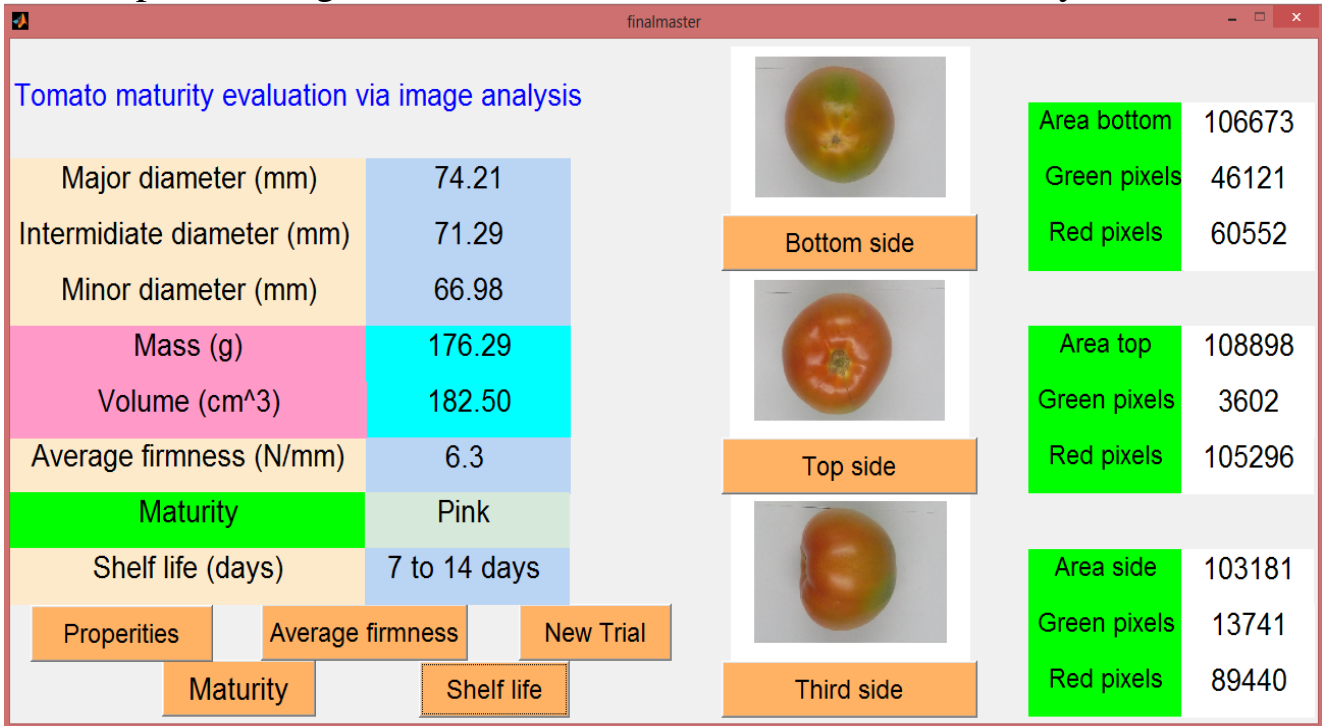

Figure 9: Tomato stage (pink).

Determination of shelf life: After we get tomato maturity, shelf life of tomato can be predicted as compared to table $\mathbf{1}$.

Table 1:-Tomato shelf life; Boyette et al. (2007)

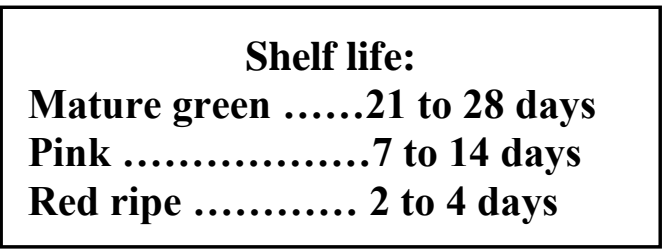

\section{RESULTS AND DISCUSSION}

\section{Effect of tomato maturity on firmness}

Force-deformation curves were obtained for each fruit as shown in figure 10. Tomato rupture force and firmness were measured, calculated, statistically, analyzed, and represented in graphics discussed in the following. 

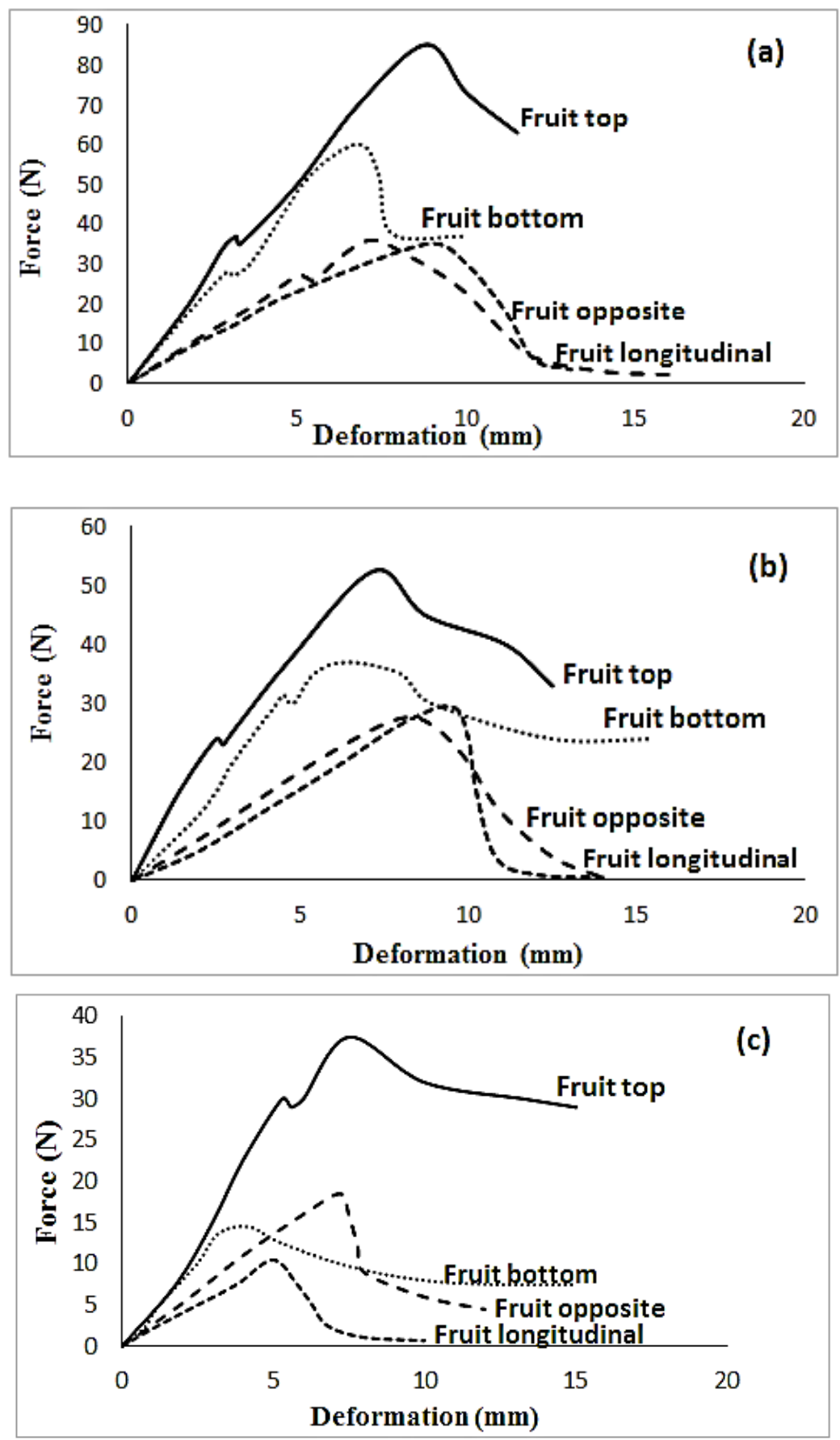

Figure $10 \mathrm{a}, \mathrm{b}$, c: Force -deformation curve obtained from the puncture test at green (a), pink (b), and red (c) maturity stages and four location probe penetration (A, B, C, D) respectively. 
Figure 11 shows the change of the firmness obtained by the puncture test. These parameters are the response of the skin and flesh at the point of measurement. The average firmness decreased significantly during fruit ripening. Average firmness (as determined by the puncture test) was determined by the steepness of the force-deformation profile, which characterized the resistance to deformation under a load up to the point of sudden fracture Bourne et al. (1966).

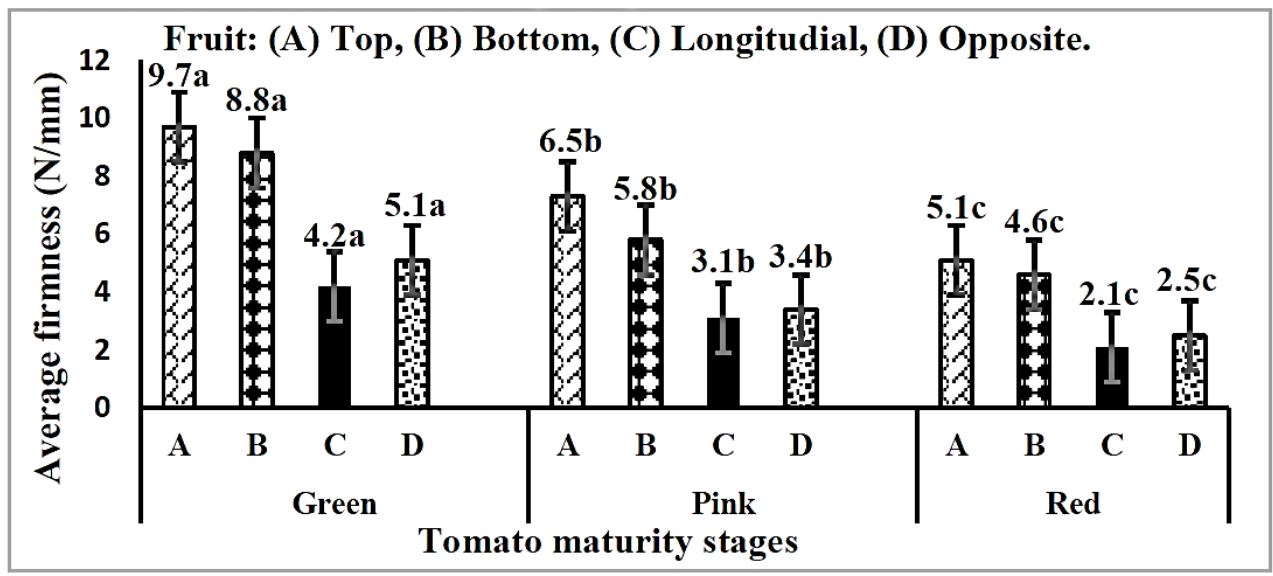

Figure 11: Tomato firmness obtained from the puncture test. Data are the mean values with the error bar indicating the standard deviation. Values with the different letters in each parameter indicate significant differences at 95\% confidence level using Duncan's multiple range test.

Sirisomboon et al. (2012) also obtained similar results with a universal testing machine device for evaluating tomato textural mechanics during maturity. The rupture force shown in figure 12, which measured the strength of the peel, indicated that the peel strength of the unripe fruit was higher than that of the ripe one. The toughness, i.e., the energy required to break the peel of intact fruit, corresponded to the rupture force. This indicated that the peel of the fruit was more prone to rupture at the late stage than at the early stage.

Figure 12 shows that rupture force changes from green stage to pink stage by $10 \%, \mathbf{5 1 \%}, \mathbf{2 6 \%}$, and $\mathbf{2 5 \%}$ for top, bottom, longitudinal, and opposite respectively. On the other hand, rupture force changes from green stage to red stage by $\mathbf{1 5 \%}, \mathbf{7 5 \%}, \mathbf{6 5 \%}$, and $\mathbf{5 6 \%}$ from top, bottom, 
longitudinal, and opposite side respectively. And the change in rupture force from green to pink and from green to red at bottom was high at $\mathbf{5 1 \%}$ and $\mathbf{7 5 \%}$, respectively. This indicates that the bottom was more sensitive to the maturity stages than the others three position.

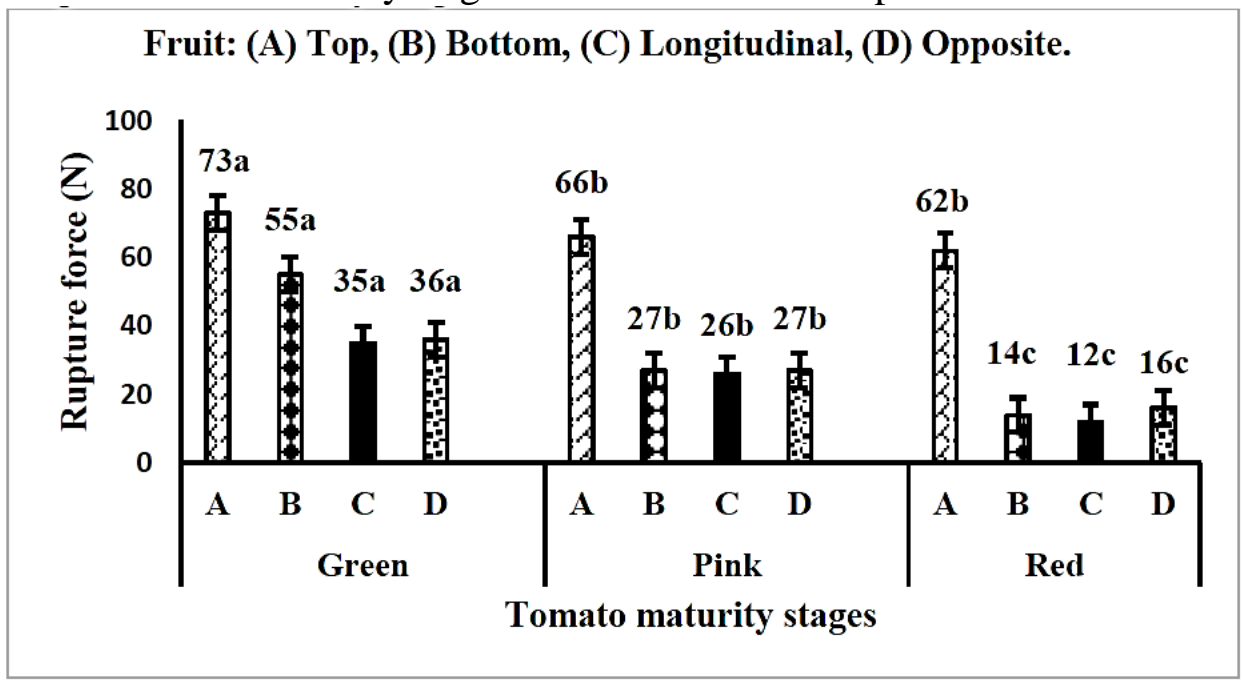

Figure 12: Tomato rupture force obtained from the puncture test. Data are the mean values with the error bar indicating the standard deviation.

Figure 13 shows that a sharp increase between stages (green to red) with red intensity changing from green stage to red, as a consequence of both, chlorophyll degradation and lycopene synthesis Lopez Camelo and Gomez (2004). In addition, rupture force decreased generally from green to red stage. So image analysis is accurate to Judge the tomato maturity stages.

\section{Classification test}

Fresh tomatoes used in classification test were picked at three stages of maturity. Abnormally shaped and defective tomatoes were rejected. Subsamples of 20 tomatoes for each of three maturity stages were manually selected based on the USDA color chart, for a total of 60 tomatoes. Images were obtained and processed by the image analysis technique. Tomato samples were classified into one of the three maturity stages. Table 2 summarizes maturity classification results using the image analysis compared to manual grading results. Among the 60 tomatoes tested, 59 tomatoes, or $98 \%$, were correctly classified. 


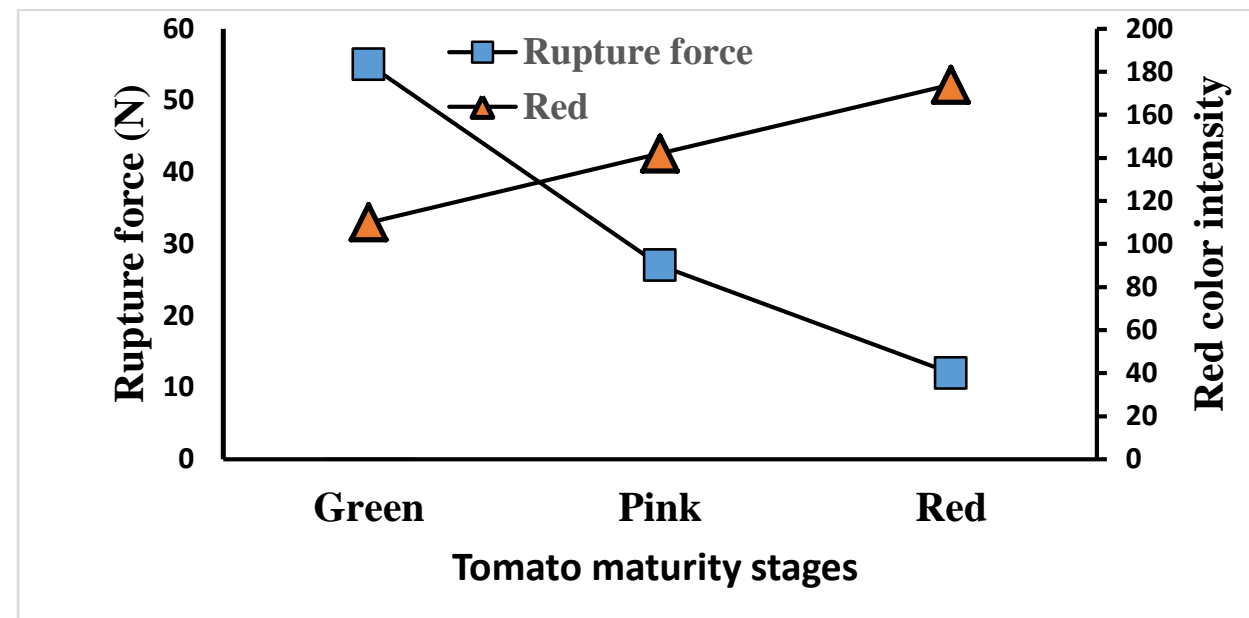

Figure 13: Measured tomato fruit's rupture force at fruit bottom location at different maturity stages.

Table 2: Maturity classification results by manual and image analysis classification.

Manual grading

Image analysis classification

\begin{tabular}{cccc}
\hline Green & Pink & Red & Total \\
20 & - & - & 20 \\
- & 19 & 1 & 20 \\
- & - & 20 & 20 \\
20 & 19 & 21 & 60
\end{tabular}

\section{Comparison of image processing method with vernier caliber.}

The results of comparison between determined IP (pixel) and measured dimensions $(\mathrm{mm})$ of tomato fruits are shown in figure 14. These results can be employed in systems after harvesting such as ones which make grading by quality and size. Other than that, they can be even useful before -harvesting processes for detecting fruit growing stages. And to design a machine of handling, cleaning, conveying and storage. The physical properties such as dimensions of agricultural products must be known. 


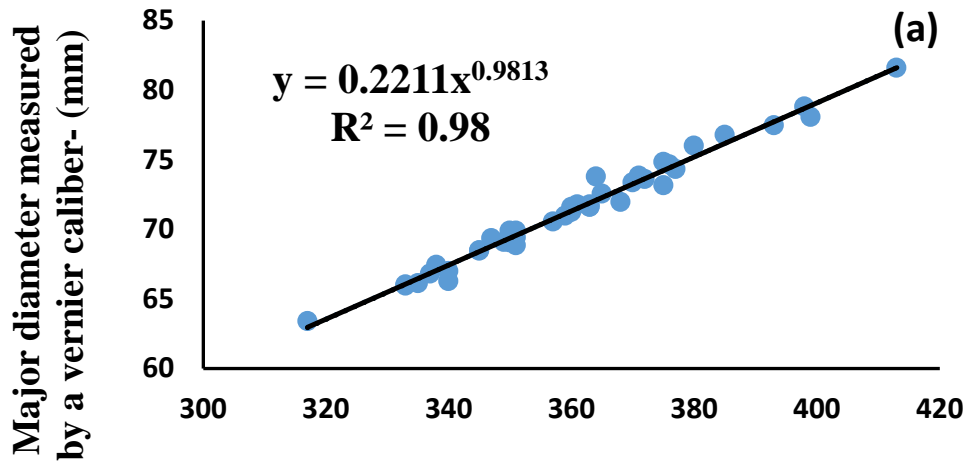

Major diameter determined by IP- (pixel)

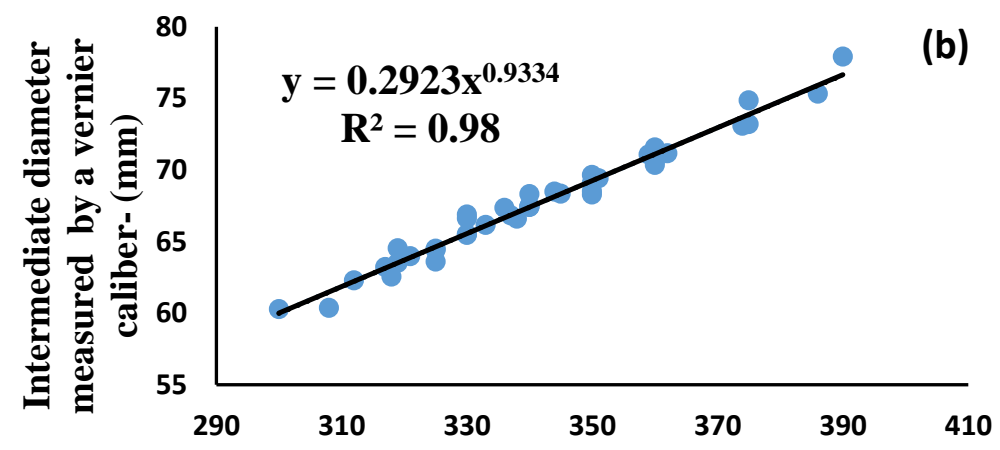

Intermediate diameter determined by IP- (pixel)

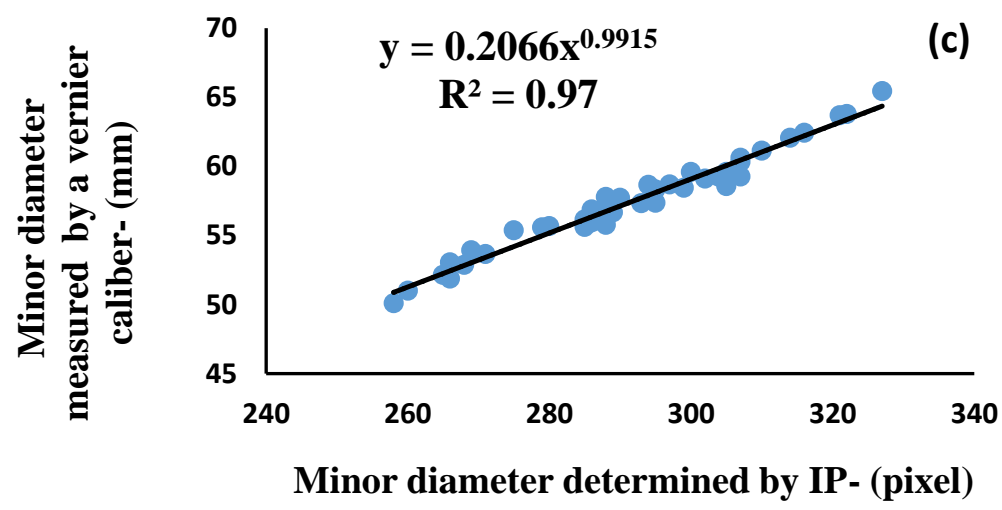

Figure 14 a, b, c: Comparison of determined tomato fruit's dimensions at major (a), intermediate (b) and minor diameter (c) by IP with vernier caliper. 


\section{SUMMARY AND CONCLUSION}

A color image analysis procedure was built to classify fresh tomato into three maturity stages according to the USDA standard classification: green, pink and red. The maturity stages were determined based on the green: red color ratio. For both, the algorithm and image processing function in MATLAB 2012a are used to process the images. System performance was evaluated by comparing the classification results with manual grading. As response rupture force, average firmness at four locations (on the fruit top, bottom and two symmetric points of each sample) and dimensions were determined to compare the results with image analysis. Classification results agreed with manual grading in $98 \%$ of the tested tomatoes. Also, it is worth mentioning, that the algorithm utilized is less complicated and more processor friendly than the manual grading. This indicates that the judgment of tomato maturity was simple, accurate and low-cost in this study using image processing and can be easily implemented in sorting of tomato during post-harvest processing.

\section{REFERENCES}

Atherton, J. G. and Rudich, J., 1986. The Tomato Crop, Chapman and Hall Press: 260-273.

Batu, A., 1998. Some Factors Affecting on Determination and Measurement of Tomato Firmness. Tr. J. of Agriculture and Forestry, 22: 411-418.

Batu, A., 2004. Determination of Acceptable Firmness and Color Values of Tomatoes. J. of Food Eng., 61: 471-475.

Bourne, M. C., J. C. Moyer and Hand, D. B., 1966. Measurement of Food Texture by A universal Testing Machine. Food Tech. 20: 522526.

Boyette, M. D., Sanders, D. C. and Estes, E. A., 2007. Postharvest Cooling and Handling of Field and Greenhouse Grown Tomatoes. Retrieved on August 26, 2007, from http://www.bae.ncsu.edu/programs/extension/publicat/postharv/ tomatoes/tomat.html. 
Da Fontoura, L. and Marcondes, R. Jr., 2001. Shape Analysis and Classification: theory and practice. New Jersey, USA: CRC Press: 191-258.

De Grano A. and Pabico, J., 2007. Automating the Classification of Tomato (Lycopersicon esculentum) Maturity Using Image Analysis and Neural Networks. Trans. Nat. Acad. Sci. Tech. Phili., 29(1): 131-132.

Edan, Y., H. Pasternak, I. Shmulevich and Fallik, D., 1997. Color and Firmness Classification of Fresh Market. Journal of Food Science, 62(4):793-796.

Ewida, E. H., M. N. El Awady, M. A. Rashwan and ElAttar, M. Z., 2014. Computer Application on Pattern Recognition for Palm-Date Grading. Misr J. Ag. Eng., 31(2):619-630.

FAO of agricultural statistics, 2012.

http://faostat.fao.org/site/339/default.aspx.

Ghazavi, M. A., R. Karami and Mahmood, 2013. Modeling Some Physico-Mechanical Properties of Tomato. J. of Agricultural Sci., 5(1):210-223.

Hassan, H. E., A. A. Abd El-Rahman and Abdel-Hameed, U. A., 2015. Lemon Quality Evaluation during Maturity Using Color Analysis and Laser Technology. Misr J. Ag. Eng., 32(2):771-778.

Kabany, A. G., 2002. Color Image Analysis for Tomatoes Maturity Inspection. The 10th conference of the Misr Soc. of Agric. Eng.: 95102.

Kabas, O., A. Ozemerzi and Akinci, I., 2006. Physical Properties of Cactus Pear Grown Wild in Turkey. J. of food Eng., 73 (2): 198202.

Kang, S.P., A. R. East and Trujillo, F. J., 2008. Colour Vision System Evaluation of Bicolour Fruit: A case study with 'B74' mango. Postharvest Biology and Tech., 49: 77-85. 
Kilickan, A. and Guner, M., 2008. Physical Properties and Mechanical Behavior of Olive Fruits under Compression Loading. J. of Food Eng., 87 (2): 222-228.

Leon, K., D. Mery, F. Pedreschi and Leon, J., 2006. Color Measurement in L a b Units from RGB Digital Images. Food Research International, 39: 1084-1091.

Lopez Camelo, A. F. L. and P. A. Gomez., 2004. Comparison of Color Indexes for Tomato Ripening. Horticulture Brasileira, 22(3):534-537.

Mohammadia, V., K. Kheiralipour and Mahdi G., 2015. Detecting Maturity of Persimmon Fruit Based on Image Processing Technique. Scientia Horticulturae, 184:123-128.

Mohsenin, N. N., 1986. Physical Properties of Plant and Animal Materials. Gordon of Breach science publishers, New York: 79:100.

Pavithra, V., R. Pounroja and SathyaBama, B., 2015. Machine Vision Based Automatic Sorting of Cherry Tomatoes. International Conference on Electronics and Communication System: 271-275.

Sarkar, N., and Wolfe, R. R., 1985. Feature Extraction Techniques for Sorting Tomatoes by Computer Vision. Trans. ASAE 28(3): 970974,979.

Shewfelt, R. L., S. E. Prussia, V. A. Resurreccion, W. C. Hurst and Campbell, D. T., 1987. Quality Changes of Vine-Ripened Tomatoes within the Postharvest Handling System. J. Food Sci., 52(3): 661664.

Sirisomboon, P., M. Tanaka, T. Kojima, and William, P., 2012. Nondestructive Estimation of Maturity and Textural Properties on Tomato 'momotaro' by Near Infrared Spectroscopy. J. of Food Eng., 112: $218-226$.

USDA., 1976. United States Standards for Grading of Fresh Market Tomatoes. USDA Agricultural Marketing Service, Washington DC.

Zhang, Y., X. Yin, X. Zou and Zhao, J., 2009. On-line Sorting Maturity of Cherry Tomato by Machine Vision. IFIP AICT, 295: 2223-2229. 


\section{الملخص العزبي \\ تصنيف نضج الطماطم عن طريق تحليل الصور}

محمود يمانى * ، عبدالفضيل جابر القبانى ** ، محمود العطار **

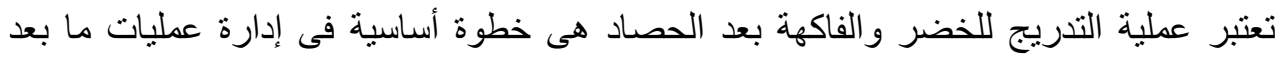

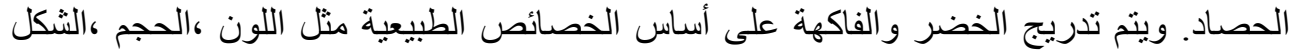

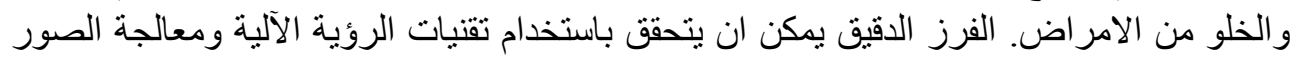

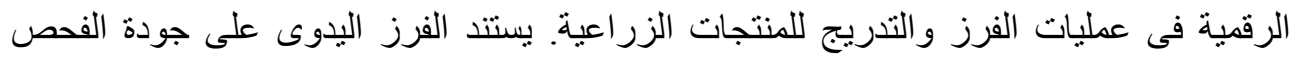

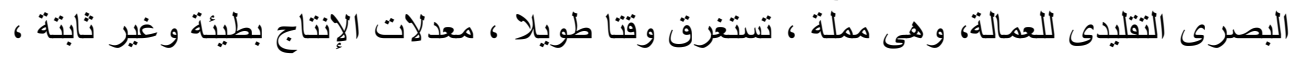

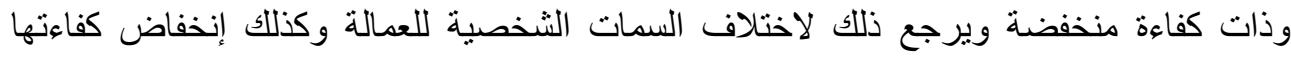

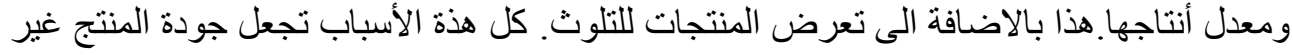

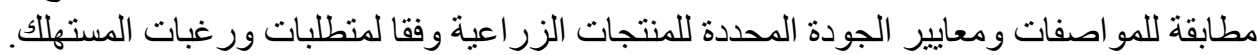

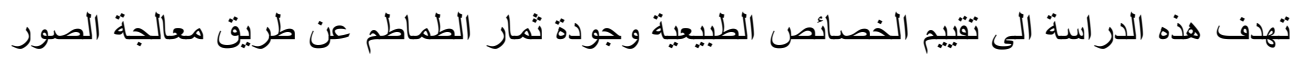

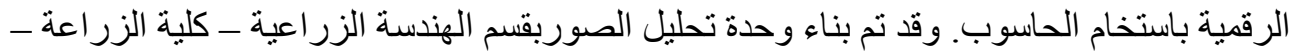

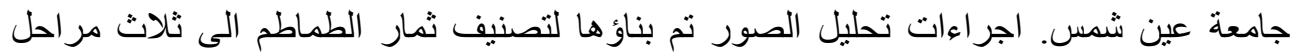

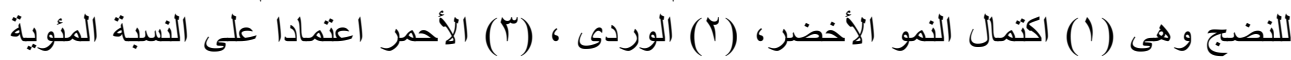

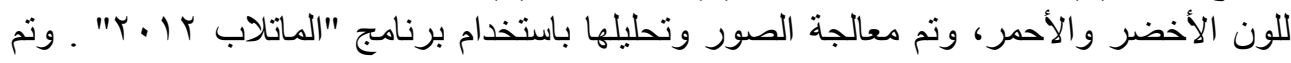

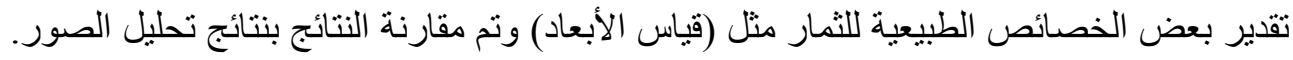

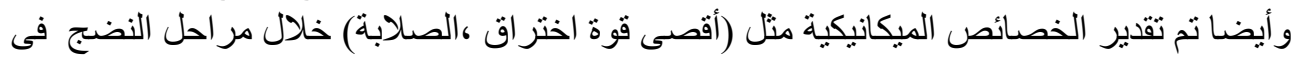

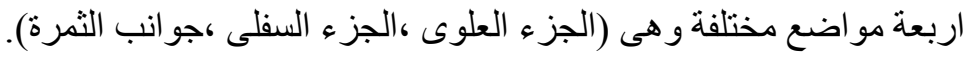

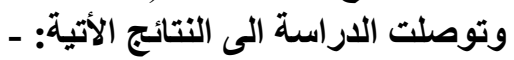

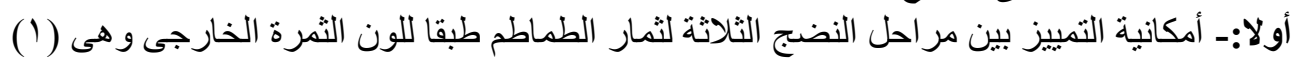

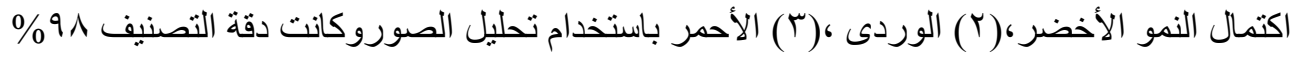

ثانيا:- أوضحت نتائج أختبار الأختراق حساسية كلا من أقصى قوة أختراق ، الصلابة لمراحل

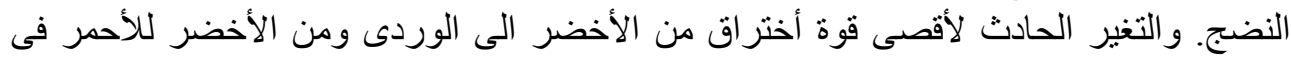

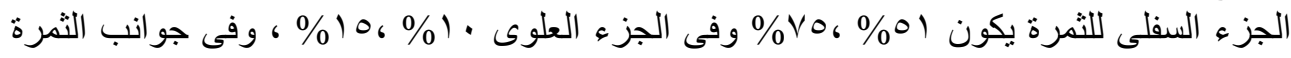

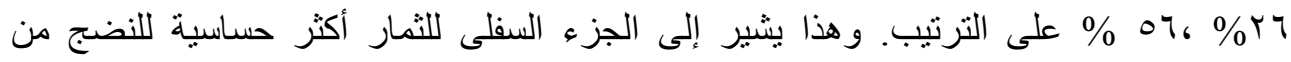

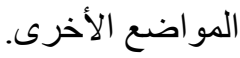

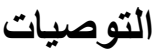

1ـ امكانية استخدام هذا النموذج لقياس أبعاد ثمار الطماطم مع تحديد درجة النضج أثناء عمليات ما

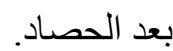

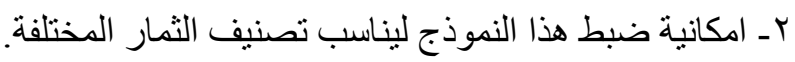
rـ امكانية دمج تقنية تحليل الصور مع نظام الرؤية الآلية للفرز الآلى للثمار فى در اسات مستقبلية. 